\title{
Effects of Morus nigra L. in Bone Healing
}

\author{
Jeferson Cardoso Costa ${ }^{1}$ Bárbara Caroliny Pereira ${ }^{2}$ Evelise Aline Soares ${ }^{3}$ \\ Nalielle Lohana Serafini Gonçalves ${ }^{4}$ Alessandra Esteves ${ }^{4}$ ( Wagner Costa Rossi Junior ${ }^{4}$
}

1 Faculdade de Medicina de Ribeirão Preto, Universidade de São Paulo,

Address for correspondence Wagner Costa Rossi Junior, PhD,

Ribeirão Preto, SP, Brasil

2 Faculdade de Enfermagem Universidade de São Paulo em Ribeirão Departamento de Anatomia, Universidade Federal de Alfenas, Minas Gerais, Brazil. Rua Gabriel Monteiro da Silva, 700, Centro, Alfenas, MG, Preto , Ribeirão Preto, SP, Brazil

${ }^{3}$ Faculdade de Medicina da Universidade Federal de Alfenas, CEP 37130-000, Brasil (e-mail: wagnerunifal@gmail.com).

Alfenas, MG, Brazil

${ }^{4}$ Department of Anatomy, Universidade Federal de Alfenas,

Alfenas, MG, Brazil

J Morphol Sci 2019;36:286-290.

\begin{abstract}
Keywords

- healing bone

- morus

- bone fracture

- medicinal plants

Morus nigra L., popularly known as blackberry, mulberry or blackberry bush, is a plant species widely used by folk medicine. Although there are few scientific studies that denote its therapeutic features, an important highlight of black mulberry is the recurrent use of tea leaves in popular environment for treatment of climacteric because it is considered a source of substances with estrogenic activity, which, if deficient, decreases osteoblastic action. Thus, the objective of the present study was to analyze the effect of the infusion of the leaves of $M$. nigra L. on bone repair experimental models. Twenty female Wistar rats (Rattus norvegicus), $\sim 100$ days old, were submitted to fracture with bone loss in the left fibula. After that, they ingested tea leaves of $M$. nigra L. for 30 days without interruption. The animals suffered euthanasia after the treatment period. The results showed a significant healing of fractures in all animals that ingested the tea, when compared with other groups. In this way, it is possible to suggest that $M$. nigra $L$. tea is able to trigger a positive response in bone repair mechanism; however, it is not possible to state at what level this positive interference occurs, since mechanisms of its action have not yet been elucidated, thus requiring more specific studies on the phytotherapeutic effects of this plant.
\end{abstract}

\section{Introduction}

Medicinal plants are plant species that contain in their structure one or more active principles that can be used as precursors of substances used for therapeutic purposes in alternative medicine. ${ }^{1}$ They have been extensively investigated in experimental models all over the world, and such investigations are initiated from effects reported by the user population. ${ }^{2}$

Morus nigra $L$., popularly known as mulberry, blackberry or blackberry bush, is a plant species widely used by folk medicine. M. nigra L. belongs to the genus Morus, family Moraceae, which includes $\sim 24$ species and at least around 100 known varieties of this plant around the world. It is found mainly in temperate and subtropical regions and may develop in various climatic conditions. ${ }^{3}$

This plant is present in different areas of Brazil, being especially mentioned for its medicinal characteristics. Studies have reported positive effects with the use of the fruits and leaves of M. nigra L. in the treatment of pharyngitis and gastrointestinal inflammatory diseases; ${ }^{4,5}$ as laxative, sedative, expectorant, refreshing, emollient, soothing, diuretic, hypoglycemic, and antiinflammatory; ${ }^{3,4}$ in the treatment of diabetes; ${ }^{6}$ as analgesic; ${ }^{7}$ it has protective action against peroxidative damages of biomembranes and biomolecules; ${ }^{8}$ it has antinociceptive and anti-inflammatory action; ${ }^{9}$ and, finally, it has strong antibacterial and antioxidant activity. ${ }^{10}$ received

May 21, 2019

accepted

August 8, 2019
DOI https://doi.org/

10.1055/s-0039-1698374. ISSN 2177-0298.
Copyright (e 2019 by Thieme Revinter

Publicações Ltda, Rio de Janeiro, Brazil
License terms

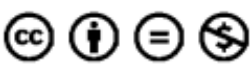


Although there are few scientific studies that denote its therapeutic functionalities, an important highlight of black mulberry is the recurrent use of the tea from its leaves in popular milieu. The results obtained through an ethnomedicinal research performed in the municipality of Muriaé, MG, confirmed the use of $M$. nigra $L$. in the treatment of climacteric symptoms, with a considerable consensus on popular use (> $50 \%$ ), which led us to conclude that $M$. nigra L. may have medicinal potential for chemical and pharmacological studies, especially as a source of substances with estrogenic activity. ${ }^{11}$

During menopause, low estrogen production decreases the activity of osteoblasts, making osteoclast activity exacerbated. Thus, bone matrix resorption occurs, which, in turn, releases calcium, causing bone demineralization and favoring the onset of osteoporosis. ${ }^{12}$

Due to uncertainties regarding the effects of $M$. nigra $\mathrm{L}$. regarding its possible action in osteoporosis and bone metabolism, the objective of the present study was to analyze the effect of the infusion of the leaves of $M$. nigra L. in experimental models of fracture with bone substance loss.

\section{Material and Methods}

Twenty female Wistar rats (Rattus norvegicus) were used in this study, $\sim 100$ days old, from the Universidade Federal de Alfenas (UNIFAL), lodged in cages containing only one animal, treated with commercial ration, water or tea ad libitum, and kept in 12-hour light-dark cycles. Every day, the animals were placed with others for a period of 2 hours, so that the socialization was not compromised. The project was submitted to the animal ethics committee of Universidade Federal de Alfenas, MG, and approved with protocol number 52/2016.

The leaves of M. nigra L. were obtained commercially in natural products stores. The infusion was performed by mechanical maceration, in proportion of $20 \mathrm{~g}$ fresh leaves per $200 \mathrm{ml}$ of water, at $90^{\circ} \mathrm{C} .{ }^{13}$ The preparation was made daily and offered to the animals every morning.

The animals were divided into four (4) experimental groups $(n=5)$ :

GI: Animals treated with water/without bone fracture;

GII: Animals treated with tea/without bone fracture;

GIII: Animals treated with water/with bone fracture;

GIV: Animals treated with tea/with bone fracture.

\section{Treatment}

The treatment consisted in the administration of an infusion of the leaves of $M$. nigra L. for 30 days without interruption; the infusion was available in the morning, with average amount of $120 \mathrm{ml}$ per bottle, in each cage, for free consumption. In the following morning, the residual volume was measured to evaluate the amount ingested by each animal. The researchers chose not to use the oral gavage method due to the high stress rate that such a procedure generates on animals, which could interfere with their recovery. A study using the implanted telemetry method was able to demonstrate that the acute effect of gavage in rats may persist for 30 to 60 minutes after the end of the procedure. ${ }^{14}$ The animals underwent surgery on the first day of the treatment with the infusion, to remove a fragment measuring 2 to $3 \mathrm{~mm}$ of the left fibula, which was used to analyze the bone regeneration process.

\section{Surgical Technique for Removal of Fibular Fragment}

For removal of the fibular fragments, the animals were anesthetized with intraperitoneal injection with a mixture of ketamine hydrochloride $\left(\right.$ Ketalar $^{2}$ - $50 \mathrm{mg} / \mathrm{ml}$ - Pfizer, New York, NY, USA) and xylazine hydrochloride (Rompum ${ }^{2}$ $2 \mathrm{~g} / 100 \mathrm{ml}$ - Bayer, São Paulo, SP, Brazil] at a dose of $0.20 \mathrm{ml} /$ $100 \mathrm{~g}$ of weight and $0.10 \mathrm{ml} / \mathrm{kg}$ of weight, respectively. Then, at the surgery site, trichotomy and asepsis were performed with polyvinylpyrrolidone iodine (PVPI). The incision was made on the side of the animal's leg using scalpel cable number 3 and blade number 11. The subcutaneous tissues were removed for visualization of the fascial plane. The muscle fascia was incised, and the muscles were carefully removed for exposure of the fibula. At the level union of the proximal third with the middle third in the fibula diaphysis, a fragment with 2 to $3 \mathrm{~mm}$ of bone was removed, measured with aid of a millimeter endodontic rule. The section of fibula was carefully made with a cuticle plier, having the aim of traumatizing as little as possible and avoiding, above all, flaking the sectioned end. In this way, two bone fragments or stumps were always left, one proximal and one distal ( - Fig. 1). After sectioning, the site was rinsed with sterile saline for complete removal of possible bone particles that may or may not have detached. Subsequently, the tissues were repositioned, and the skin was sutured with a 3.0 silk thread. Finally, and immediately after the surgery, the animals received a dose of dipyrone $(50 \mathrm{mg} / \mathrm{kg})$ intraperitoneally.

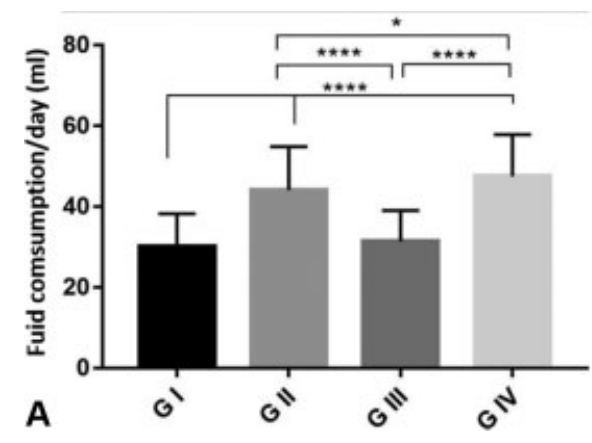

\begin{tabular}{cc}
\hline Group & Fluid comsumption (mI) \\
\hline I & 30,03 \\
II & 44,03 \\
III & 31,43 \\
IV & 47,48 \\
\hline
\end{tabular}

Fig. 1 (A) Daily net consumption by the animals of 4 groups analyzed. (B) Mean values of fluid consumption $(\mathrm{ml}) .{ }^{*} p<0.05 ;{ }^{* * * *} p<0.0001$. 


\section{Euthanasia and Sample Preparation}

The animals underwent euthanasia 30 days after surgery by anesthetic overdose method, and, at that moment, they received cardiac perfusion of $4 \%$ buffered paraformaldehyde. After euthanasia, the left hind limbs were removed and placed for another 24 hours in same paraformaldehyde solution, for complete tissues fixation. Later, the left fibulas were dissected and separated from the tibias and then X-rayed using occlusal $\mathrm{X}$-ray films with a time of $\mathrm{X}$-ray exposure of 0.8 seconds in dental X-ray devices.

The fibulas were placed in a descaling solution (formic acid $P A+20 \%$ sodium citrate, $1: 1$ ratio) for 30 days. After the process of decalcification, the fibulas were processed following the standardized sequence in conventional histological procedures: alcohol dehydration, xylol diaphanization and paraffin inclusion. Each fibula was secured and cut with a thickness of $7 \mu \mathrm{m}$ in Lupe microtome (Lupe Indústria Tecnológica de Produtos para Laboratório LTDA, São Carlos, SP, Brazil) and stained with hematoxylin and eosin (H\&E) for later analysis.

The present study represents a completely randomized design (CRD); therefore, the statistical analysis was performed through an analysis of variance (one-way analysis of variance [ANOVA]) followed by Tukey averages comparison test, and values of $p<0.05$ were considered as indicative of significance.

\section{Results}

In the analysis of the daily consumption of liquids, during 30 days of treatment of the 4 groups evaluated, some interesting data were observed that probably denote the positive effect of tea in the process of bone regeneration. It was possible to observe that the ingestion of liquid in groups GII and GIV, which ingested the tea, was noticeably superior to the water content ingested by GI and GIII, proving the good acceptance of tea by animals ( $\mathbf{- F i g . 1}$ ). Because it was offered in ad libitum regime, the gavage method was not necessary. Thus, contrary to many published works, the acceptance of tea by animals is excellent, requiring only the daily control of the intake.

The results found in the evaluation of the effect of M. nigra $\mathrm{L}$. tea on bone regeneration were very satisfactory. Radiographic

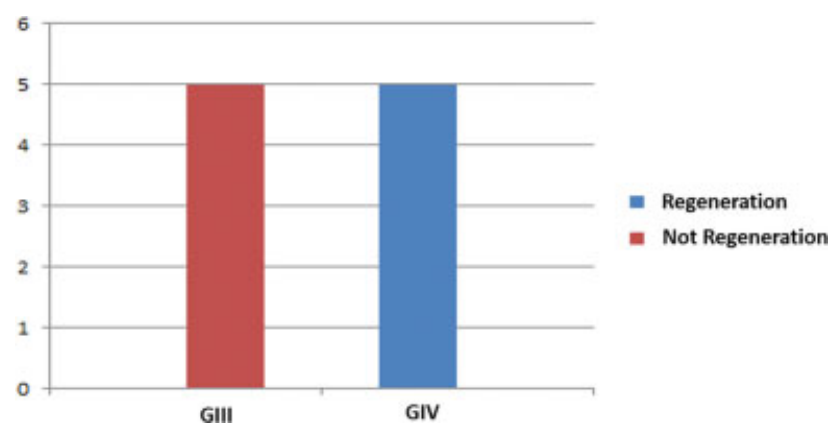

Fig. 3 Animals operated and treated with water/tea that presented or not regeneration after 30 days of the experiment. $Y$ axis: quantity of animals.

and histological analysis of fractured left fibulas and biomechanical analysis of right tibias were performed.

The control groups, GI, with water intake, and GII, with tea intake, remained normal when analyzed radiographically. -Fig. 2A represents the normal bone structure of the fibula observed in both groups.

-Fig. 2B e 2C show, respectively, the radiographic appearance in an animal of GIV and an animal of GIII. It is noticed that the bones of the animals in GIV do not yet present the radiographic appearance of a control animal; however, the union between the two fracture stumps can be clearly observed, which does not happen with the animals of GIII. Thus, it can be assumed that the M. nigra L. tea had an active and positive action on the mechanism of bone regeneration.

These same results were not observed for GIII and GIV, who underwent surgery to perform the fracture. - Fig. 3 shows the results obtained by radiographic analysis. It can be observed that, in GIV (animals treated with tea and that suffered fractured), complete regeneration of the bone fracture occurred in all the animals, although different in relation to control groups, which was not observed in animals of GIII (animals treated with water and that suffered fracture), which did not demonstrate regeneration in any animal. It is clear that the tea had a positive effect in promoting, facilitating, and accelerating the regeneration of bone defects, which, although radiographically different from those in the control groups, had already been fully formed.
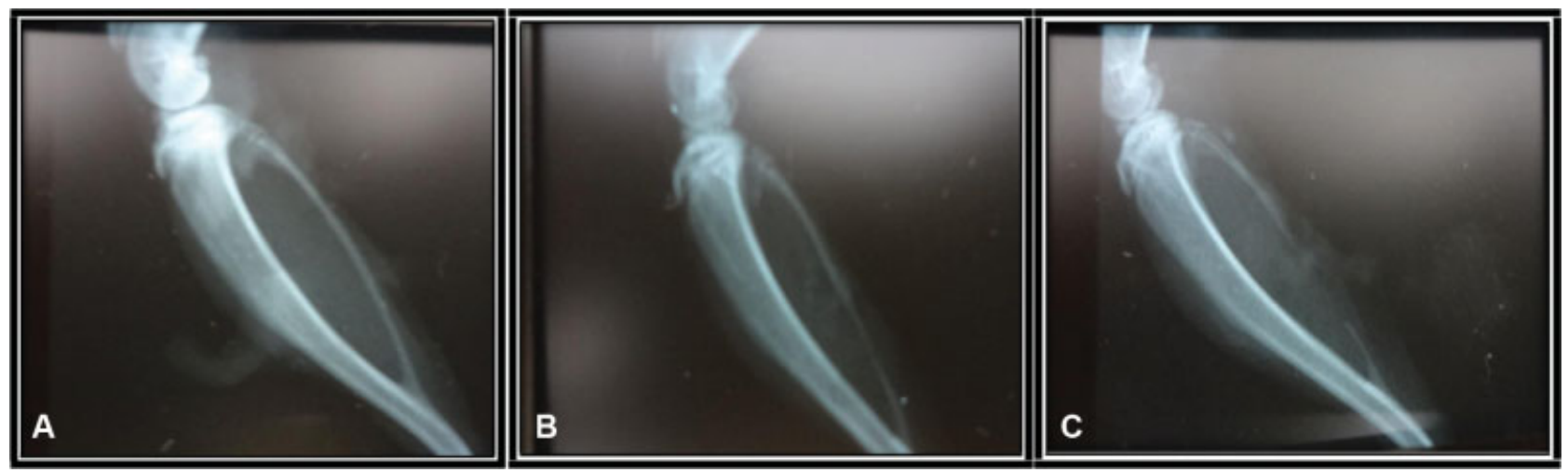

Fig. 2 (A) Radiographic bone integrity seen in GI and II. (B) Radiographic appearance of a regenerated fibula in an animal of G IV. (C) Radiographic appearance of an unregenerate fibula in an animal of GIll. 


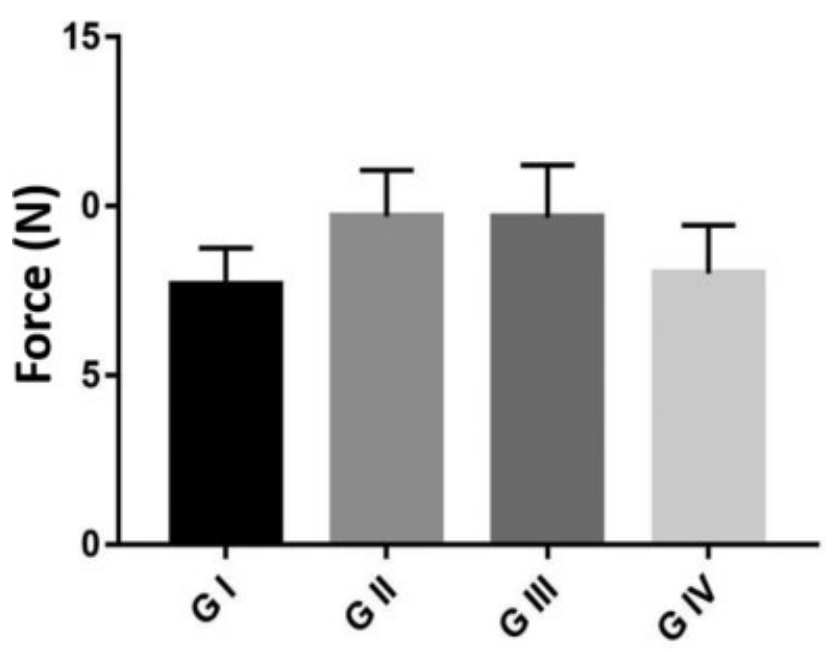

Fig. 4 Biomechanical analysis of right tibia in experimental groups.

The biomechanical analysis of the right tibia in GI, GII, GIII, and GIV was performed to verify if $M$. nigra L. tea could make the bone structure more mineralized and, consequently, make it more resistant to mechanical forces. However, the test did not present any significant results, as shown in - Fig. 4. It can be observed that resistance to the incidence of pressure force on the bones was statistically equivalent in both groups, when these were compared.

The evaluation of histological sections showed the same results obtained by radiographic visualization, that is, in all animals that presented regeneration in radiographs, young bone was observed between the fracture stumps. In those in which there was no radiographic consolidation, only fibrous and muscular tissue was visualized between the fracture stumps. If cartilage islands were visualized in the center of the defect, or if cartilaginous tissue was observed between the fracture stumps, it could be attributed only time ques- tion, so that complete regeneration could occur. The existence of other tissues in one defect area, besides not being part of the regeneration, also participated as a mechanical obstacle, which prevented the growth and consolidation of the fracture (-Fig. 5). Thus, the tea contributed to accelerate healing, preventing onset of fibrosis, which would compromise the repair process.

\section{Discussion}

Black mulberry (M. nigra L.) is an Asian plant that has some phytosteroids and, among them, phytoestrogens (isoflavones). These substances, although presenting different chemical structures than those of of estrogens, act in a similar way in animal organisms. ${ }^{15}$ Phytoestrogens have a phenolic ring in their structure, and this structural component is related to their binding to estrogen receptor. ${ }^{16}$ Alpha-type estrogen receptors are found primarily in the breast and uterus, and $\beta$ receptors in the bone and cardiovascular system, with estradiol having affinity with both receptors. $^{17}$

Recently, the presence of flavonoids (isoflavones) in the composition of M. nigra L., besides alkaloids and tannins, has been proven. Flavonoid-rich plants may play a positive role in antitumor, antiinflammatory, antioxidant, anti-hemorrhagic, and hormonal treatment. ${ }^{18}$ Based on these facts, these substances could have a connection in the $\beta$-estrogen receptors of bones and stimulate their metabolism, since in this study, all fractured animals that took blackberry tea had complete bone regeneration.

Sexual hormones, both male (testosterone) and female (estrogen), have a potent effect on the bones and are generally stimulators of bone tissue formation. These hormones influence the appearance and development of ossification centers. Estrogens are known to inhibit osteoclast activity in the bone, thereby stimulating bone growth.
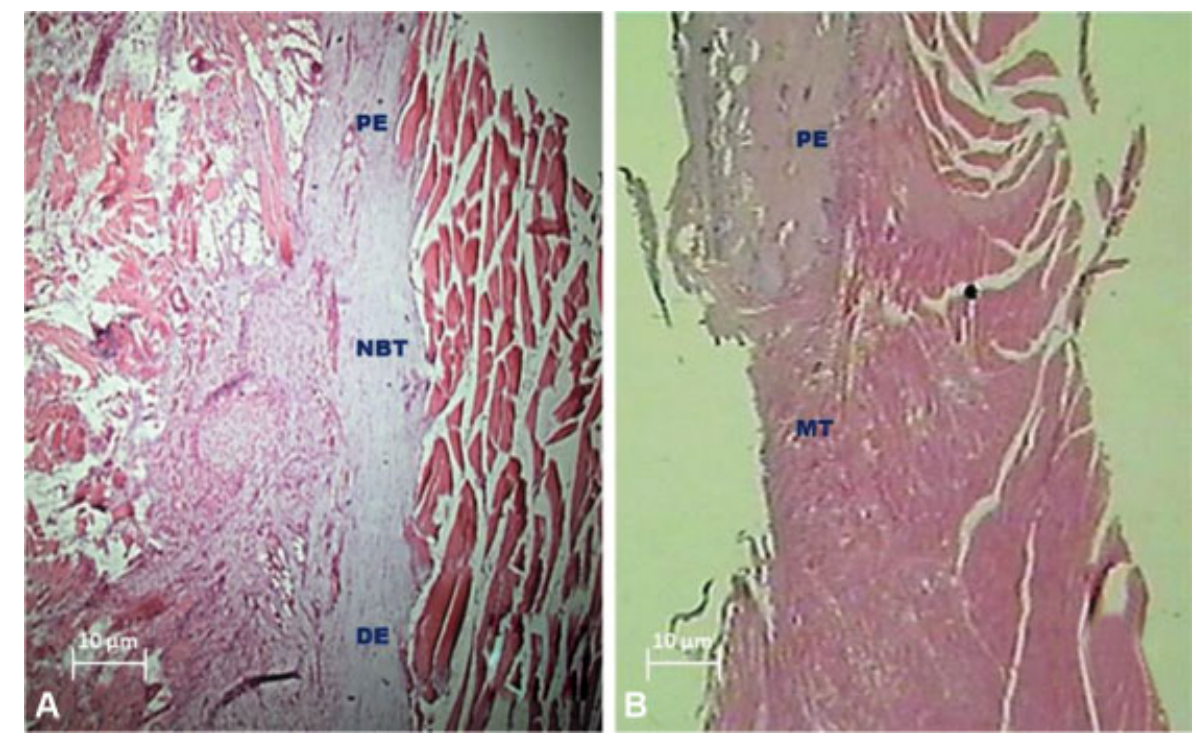

Fig. 5 Microscopic appearance of bone defect region. (A) animal treated with Morus nigra leaves infusion with complete bone defect healing (PE - proximal end; NBT- new bone tissue; DE -distal end); (B) animal without infusion treatment with muscle tissue filling the area of bone defect (PE - proximal end; MT - muscular tissue). 
Part of this effect is due to stimulation of osteoprotegerin, also called the inhibitory factor of osteoclastogenesis, a cytokine that inhibits bone resorption, thus favoring the action of osteoblasts and leading to an increase in bone mass. Osteoblasts are responsible for osteogenesis, that is, for synthesis and secretion of organic matrix, as well as storing minerals and coating most of the bone surfaces. ${ }^{19,20}$ This mechanism occurs throughout the growth of the individual and can be activated also in cases of lesions to the bone tissue.

Thus, it is possible to suggest that blackberry tea has a very positive osteogenic effect, since none of the fractured animals failed to reach complete regeneration. A possible mechanism of action would be estrogen rate increase and stimulation of antiosteoclastogenic factors. In this context, the data found in this research are in agreement with those presented in the literature, since the animals that underwent surgery and received treatment with the infusion of M. nigra L., presented a potential of bone repair superior to the animals that were submitted to surgery and did not receive the infusion. By means of this information, it is possible to suggest that blackberry tea has a very considerable osteogenic effect, since in all fractured animals, the regeneration was totally complete. A possible action mechanism would be the increase of estrogen rate and stimulation of anti-osteoclastogenic factors, especially by action of osteoprotegerin, which, of course, allows more osteoblastic activity and acceleration of regeneration process. In this sense, it would be extremely interesting to use this infusion in those situations in which there is a reduction of bone mineral density or bone metabolism rate, since osteogenic activity could be favored.

However, it is necessary to carry out a more detailed investigation, based mainly on specific biochemical and molecular tests, to better elucidate the effect caused by the infusion of leaves of M. nigra L. on bone tissue, and which action mechanisms would be involved, since it is a substance of popular use and knowledge, that is easy to obtain, has a low cost, is very palatable and presents very positive results in the process of bone regeneration.

\section{Conclusion}

According to the results obtained in this study, it is possible to affirm that process he tea of the leaves of M.nigra L. was able to trigger a positive response in the mechanism of bone repair. However, it is not possible to determine the active principle responsible for this action, since many structural components of $M$. nigra L. have not yet been isolated, quantified, and analyzed, thus requiring a more detailed study of the pharmacological potential of this plant.

Conflicts of Interest

The authors have conflicts of interest to declare.

\section{References}

1 Zucchi MR, Oliveira Júnior VF, Gussoni MA, Silva MB, Silva FC, Marques NE. Levantamento etnobotânico de plantas medicinais na cidade de Ipameri - GO. Rev Bras Pl Med 2013;15(02):273-279. Doi: 10.1590/S1516-05722013000200016

2 Volpato GT, Calderon IM, Sinzato S, Campos KE, Rudge MV, Damasceno DC. Effect of Morus nigra aqueous extract treatment on the maternal-fetal outcome, oxidative stress status and lipid profile of streptozotocin-induced diabetic rats. JEthnopharmacol 2011;138(03):691-696. Doi: 10.1016/j.jep.2011.09.044

3 Ercisli S, Orhan E. Chemical composition of white (Morus alba), red (Morus rubra) and black (Morus nigra) mulberry fruits. Food Chemistry 2007;103(04):1380-1384. 1. https://doi.org/10.1016/ j.foodchem.2006.10.054

4 Lorenzi $\mathrm{H}$, Matos FJA. Plantas medicinais no Brasil: nativas e exóticas cultivadas. 2. ed. Nova Odessa: Instituto Plantarum; 2008

5 Sengul M, Ertugay MF, Sengul M. Rheological, physical and chemical characteristics of mulberry pekmez. Food Control 2005;16(01):73-76. Doi: 10.1016/j.foodcont.2003.11.010

6 Soufleros EH, Mygdalia AS, Natskoulis P. Characterization and safety evaluation of the traditional Greek fruit distillate 'Mouro' by flavor compounds and mineral analysis. Food Chem 2004; 86:625-636. Doi: 10.1016/j.foodchem.2003.11.006

7 de Souza MM, Bittar M, Cechinel-Filho V, et al. Antinociceptive properties of morusin, a prenylflavonoid isolated from Morus nigra root bark. Z Naturforsch C 2000;55(3-4):256-260

8 Naderi GA, Asgary S, Sarraf-Zadegan N, Oroojy H, Afshin-Nia F. Antioxidant activity of three extracts of Morus nigra. Phytother Res 2004;18(05):365-369. Doi: 10.1002/ptr.1400

9 Souza GR, Silva JC, Oliveira-Júnior RG, et al. Atividade antinociceptiva do extrato etanólico das folhas de Morus nigra L. (Moraceae). Rev Cienc Farm Basica Apl 2015;36(01):137-142

10 Souza GR, Oliveira-Junior RG, Diniz TC, et al. Assessment of the antibacterial, cytotoxic and antioxidant activities of Morus nigra L. (Moraceae). Braz J Biol 2018;78(02):248-254. Doi: 10.1590/15196984.05316

11 Miranda MA, Vieira GDV, Alves MS, Yamamoto CH, Pinho JJRG, Sousa OV. Uso etnomedicinal do chá de Morus nigra L. no tratamento dos sintomas do climatério de mulheres de Muriaé, Minas Gerais, Brasil. HU Revista 2010;36(01):61-68

12 Amadei SU, Silveira VA, Pereira AC, Carvalho YR, Rocha RF. Effect of estrogen defciency on bone turnover and bone repair.J Bras Patol Med Lab 2006;42(01):5-12. Doi: 10.1590/S1676-24442006000100003

13 Vanoni APNB. Avaliação da atividade fitoestrogênica do extrato hidroalcoólico e da infusão das folhas de Morus nigra L. [tese]. Porto Alegre: UFRGS; 2006

14 Atcha Z, Rourke C, Neo AH, et al. Alternative method of oral dosing for rats. JAm Assoc Lab Anim Sci 2010;49(03):335-343

15 Franco LCL. Fitoterapia em Ginecologia: quando ela é melhor que o remédio. Notícias Academia Sul-Americana de Medicina Integrada $2005 ; 7: 8-11$

16 Song TT, Hendrich S, Murphy PA. Estrogenic activity of glycitein, a soy isoflavone. JAgric Food Chem 1999;47(04):1607-1610

17 Morito K, Hirose T, Kinjo J, et al. Interaction of phytoestrogens with estrogen receptors alpha and beta. Biol Pharm Bull 2001;24 (04):351-356

18 Guizzo PL, Bredda TCC, Scarpa MVC, Navarro FF. Controle de Qualidade e triagem fitoquímica da droga vegetal das folhas de Morus nigra L. Rev Cienc Farm Basica Apl 2015;36(02):259-265

19 Guyton AC, Hall JE. Tratado de Fisiologia Médica. 13.ed. Rio de Janeiro: Elsevier; 2017

20 Compston JE. Sex steroids and bone. Physiol Rev 2001;81(01): 419-447. Doi: 10.1152/physrev.2001.81.1.419 